\title{
A comparative glycoproteome study of developing endosperm in the hexose-deficient miniature1 ( $m n 1)$ seed mutant and its wild type Mn1 in maize
}

\author{
Cecilia Silva-Sanchez ${ }^{1}$, Sixue Chen ${ }^{1,2}$, Jinxi Li ${ }^{1}$ and Prem S. Chourey ${ }^{3,4 *}$ \\ 1 Proteomics, Interdisciplinary Center for Biotechnology Research, University of Florida, Gainesville, FL, USA \\ 2 Department of Biology, UF Genetics Institute, University of Florida, Gainesville, FL, USA \\ ${ }^{3}$ United States Department of Agriculture, Agricultural Research Service, Center for Medical, Agricultural and Veterinary Entomology, Gainesville, FL, USA \\ ${ }^{4}$ Department of Agronomy, University of Florida, Gainesville, FL, USA
}

\section{Edited by:}

Gregorio Hueros, Universidad de

Alcalá, Spain

Reviewed by:

Serena Varotto, University of

Padova, Italy

Gregorio Hueros, Universidad de

Alcalá, Spain

*Correspondence:

Prem S. Chourey, United States

Department of Agriculture,

Agricultural Research Service,

1600 SW 23rd Drive, Gainesville,

FL 32608, USA

e-mail:prem.chourey@ars.usda.gov
In maize developing seeds, transfer cells are prominently located at the basal endosperm transfer layer (BETL). As the first filial cell layer, BETL is a gateway to sugars, nutrients and water from mother plant; and anchor of numerous functions such as sucrose turnover, auxin and cytokinin biosynthesis/accumulation, energy metabolism, defense response, and signaling between maternal and filial generations. Previous studies showed that basal developing endosperms of miniature1 ( $m n 1$ ) mutant seeds lacking the Mn1-encoded cell wall invertase II, are also deficient for hexose. Given the role of glucose as one of the key sugars in protein glycosylation and proper protein folding; we performed a comparative large scale glycoproteome profiling of total proteins of these two genotypes (mn1 mutant vs. Mn1 wild type) using 2D gel electrophoresis and glycosylation/total protein staining, followed by image analysis. Protein identification was done by LC-MS/MS. A total of 413 spots were detected; from which, 113 spots matched between the two genotypes. Of these, 45 showed $>20 \%$ decrease/increase in glycosylation level and were selected for protein identification. A large number of identified proteins showed decreased glycosylation levels in $m n 1$ developing endosperms as compared to the Mn1. Functional classification of proteins, showed mainly of post-translational modification, protein turnover, chaperone activities, carbohydrate and amino acid biosynthesis/transport, and cell wall biosynthesis. These proteins and activities were related to endoplasmic reticulum (ER) stress and unfolded protein response (UPR) as a result of the low glycolsylation levels of the mutant proteins. Overall, these results provide for the first time a global glycoproteome profile of maize BETL-enriched basal endosperm to better understand their role in seed development in maize.

Keywords: seed development, gene expression, sugar methabolism, transfer cells, maize

\section{INTRODUCTION}

The $m n 1$ mutation in maize is associated with a loss of $70 \%$ seed weight at maturity due to a loss-of-function mutation at the $M n 1$ locus that codes for the endosperm-specific cell wall invertase 2 (INCW2). The INCW2 protein is entirely localized in basal endosperm transfer cell layer (BETL), a major if not the sole gateway for the intake of sugars and nutrients from maternal cells into the filial tissue (Miller and Chourey, 1992; Cheng et al., 1996). Homozygous $m n 1$ mutant is not lethal presumably due to a residual low level of the cell wall invertase (CWI) activity encoded by another homolog, Incw 1 (Chourey et al., 2006). A BETL in developing maize seed is composed of two to three strata of highly specialized transfer cells (Davis et al., 1990; Kang et al., 2009), marked by a hallmark feature of labyrinth-like proliferation of cell wall called wall-in-growths (WIGs) in plants (Offler et al., 2003; Vaughn et al., 2007; Ruan et al., 2010). The INCW2 protein is immunolocalized to the $M n 1 \mathrm{WIGs}$, and the $m n 1$ mutant is associated with stunted WIG development due to the INCW2 deficiency (Kang et al., 2009). Sucrose hydrolysis is clearly a major physiological function of the Mn1-encoded INCW2 in the BETL and there is evidence that metabolically released hexoses, not exogenous, are critical as a driving force in assimilate movement between maternal and filial cells (Cheng and Chourey, 1999). As expected from the INCW2-deficiency, the $m n 1$ basal endosperm shows greatly reduced levels of glucose, fructose and sorbitol; and increased levels of sucrose relative to the $M n 1$ developing seeds (LeClere et al., 2010; Chourey et al., 2012).

Glycoproteins (GPs) have one or more covalently attached glycan (oligosaccharide, often with the presence of glucose) moieties. Nearly all $N$-linked GPs are believed to be secretory proteins, which are associated with numerous functions, including stress tolerance and cell-cell communication in development. Proteins entering the secretory pathway are marked by signal peptides; $17 \%$ of all proteins in Arabidopsis have predicted signal peptides and, $33 \%$ of these have at least one trans-membrane domain associated with the endoplasmic reticulum (ER). Addition of 
$N$-glycans to the proteins occurs as a co-translational modification at the ER and then transported through secretory pathway to the cell surface in a traffic process mediated mostly by the Golgi complex (Vitale and Boston, 2008; Liu and Howell, 2010). The ER is suggested to be a nursery where newly synthesized secretory proteins are properly decorated, modified, de-decorated (deglycosylated), finally properly folded and assembled prior to exit to their final destination (Vitale and Boston, 2008). Quality Control (QC) in this entire process is highly critical. Improperly folded proteins in the ER are causal to the so called ER-stress that is associated with unfolded protein response (UPR) - a signal transduction pathway that is well studied in mammalian and yeast cells. Recent studies in plants suggest that QC, ER stress, and UPR play an important role in biotic/abiotic stress and seed development (Liu and Howell, 2010).

The most detailed studies of GPs in maize developing endosperm have been on the storage protein zein, stored in ERderived protein bodies (Vitale and Boston, 2008; Arcalis et al., 2010). However, there is no such information on the GPs in the BETL, a cell type not associated with storage functions in seed development. Here we report the first detailed profile of the GPs in the basal endosperm using LC-MS/MS approach, a preeminent tool for identification and quantitative characterization of GPs (Ruiz-May et al., 2012). Comparative GP profiles of the BETL enriched proteins of the $m n 1$ relative to the $M n 1$ revealed potential changes due to both the hexose deficiency.

\section{EXPERIMENTAL PROCEDURES PLANT MATERIALS AND CHEMICALS}

Immature maize (Zea mays L.) kernels wild type $(M n 1)$ and miniature 1 mutant $(m n 1)$ in the W22 inbred line were harvested at 12 days after pollination (DAP). All plants were grown in the field and were self- or -sib-pollinated. At the time of harvest, kernels were individually excised from the ear with a paring knife, taking care to include undamaged base (pedicel) of each kernel. Excised kernels were flash frozen in liquid nitrogen and stored at $-80^{\circ} \mathrm{C}$ until analysis. We used the basal $1 / 3$ end of the endosperm because it is enriched for the BETL cells, the sole site of the $M n 1$ expression and also a major zone for sucrose turn-over reactions, as previously discussed (LeClere et al., 2008; Silva-Sanchez et al., 2013). All chemicals were purchased from Fisher Scientific Inc., USA unless otherwise stated.

\section{TOTAL PROTEIN EXTRACTION}

Soluble proteins were extracted from the one-third lower part of maize kernels according to a method reported by Hurkman and Tanaka (1986) with minor modifications. The frozen kernels were ground into fine powder in a pre-chilled mortar and pestle. A total of $3 \mathrm{~mL}$ of extraction buffer $(0.1 \mathrm{M}$ Tris $\mathrm{HCl} \mathrm{pH}$ 8.8, $10 \mathrm{mM}$ EDTA, 0.2 M DTT, 0.9 M sucrose) and $3 \mathrm{~mL}$ of saturated phenol were added to homogenize the sample. To extract proteins, samples were constantly agitated for $2 \mathrm{~h}$ at room temperature. The mixture was then centrifuged at $5000 \times \mathrm{g}$ for $10 \mathrm{~min}$ at $4^{\circ} \mathrm{C}$. The top clear phenol phase was removed and collected in a fresh tube. The remaining pellet was re-extracted with $3 \mathrm{~mL}$ buffered phenol solution and centrifuged again to recover the top clear phenol phase and combined with the previous fraction. The supernatant was precipitated with five volumes of ice cold $0.1 \mathrm{M}$ ammonium acetate in $100 \%$ methanol overnight and centrifuged at $20000 \times \mathrm{g}$ for $20 \mathrm{~min}$ at $4^{\circ} \mathrm{C}$. The supernatant was discarded and the pellet was washed twice with $0.1 \mathrm{M}$ ammonium acetate in $100 \%$ methanol, then washed twice with cold $80 \%$ acetone and finally with $70 \%$ of ethanol. The pellet was solubilized in isoelectric focusing (IEF) buffer (7 M urea, $2 \mathrm{M}$ thiourea, $4 \%(\mathrm{w} / \mathrm{v})$ CHAPS and $40 \mathrm{mM}$ DTT). The samples were treated with benzonase (Novagen, Gibbstown, NJ) for $30 \mathrm{~min}$ and then centrifuged at $34,000 \mathrm{rpm}$ for $30 \mathrm{~min}$ at $15^{\circ} \mathrm{C}$ using an ultracentrifuge (Optima TLX ultracentrifuge, Beckman Coulter). Supernatant was collected and $50 \mu \mathrm{L}$ aliquots were kept at $-80^{\circ} \mathrm{C}$ until use.

\section{TWO DIMENSIONAL GEL ELECTROPHORESIS, PROTEIN STAINING AND IMAGING ANALYSIS}

Protein samples were quantified using an EZQ protein quantitation kit (Invitrogen, CA, USA). Protein extracts of $500 \mu \mathrm{g}$ each were mixed with $0.2 \%$ of ampholytes ( $\mathrm{pH} 3-10)$ and loaded onto an $18 \mathrm{~cm}$ Immobilized $\mathrm{pH}$ gradient (IPG) strips ( $\mathrm{pH}$ range 3-10 NL) (GE healthcare, CA, USA), followed by overnight rehydration at room temperature. IEF was conducted on an Ettan IPGphor3 system (GE Healthcare, CA, USA) using the following conditions: $200 \mathrm{~V}$ for $30 \mathrm{~min}$, then ramping to $500 \mathrm{~V}$ for $30 \mathrm{~min}$, and finally to $10,000 \mathrm{~V}$ for $1 \mathrm{~h}$. The voltage was held at $10,000 \mathrm{~V}$ until $85,000 \mathrm{Vh}$ were reached in order to ensure complete separation and focusing of the proteins. After IEF, the strips were equilibrated for $15 \mathrm{~min}$ in equilibration buffer $(6 \mathrm{M}$ urea, $75 \mathrm{mM}$ Tris- $\mathrm{HCl} \mathrm{pH}$ 8.8, 29.3\% glycerol, 2\% SDS, 0.002\% bromophenol blue) containing $2 \%$ DTT, and for another $15 \mathrm{~min}$ in equilibration buffer containing 2.5\% iodoacetamide. The IPG strips were placed onto $18 \mathrm{~cm} 12.5 \%$ SDS gels (Jule Biotechnologies INC, Milford, CT, USA). Electrophoresis was run at $15 \mathrm{~W}$ for $5 \mathrm{~h}$. A total of three replicate 2-DE experiments were conducted for each sample.

After gel electrophoresis, staining with a glycoprotein-specific stain Pro-Q Emerald fluorescent dye was performed according to manufacturer's instructions (Invitrogen, CA, USA). Images were acquired using the Investigator ProPic unit equipped with a UV light-box (Genomics solutions, MI, USA). Then, the gels were destained and restained with a total protein dye Sypro Ruby following manufacturer's instructions (Invitrogen, CA, USA). Images were acquired with the Investigator ProPic unit. Spot detection, matching and quantification across the replicate gels of wild type and mutant samples, were done using a Progenesis Samespot Software (Non-linear Dynamics, CA, USA). The function of automatic spot detection and matching was used, followed by manual inspection. Protein experimental molecular weights were calculated using a CandyCane ${ }^{\mathrm{TM}}$ molecular mass standard (Invitrogen, CA, USA) separated in a separate lane on the 2D gels, and the experimental isoelectric points were determined based on IPG strip specifications. Normalized spot volumes were used to determine the quantitative changes of glycosylated/total protein ratios and total protein levels. ANOVA test was used to determine the statistical significance. 


\section{PROTEIN IDENTIFICATION USING LIQUID CHROMATOGRAPHY TANDEM MS (LC-MS/MS)}

Selected 2D gel spots were excised using an Investigator ProPic robot (Genomics Solutions Inc., USA) and digested with trypsin as previously described (Sheffield et al., 2006); The lyophilized peptides were resuspended in $15 \mu \mathrm{L}$ of loading buffer (3\% acetonitrile, $0.1 \%$ acetic acid, $0.01 \%$ trifluoroacetic acid) and loaded onto a C18 capillary trap cartridge (LC Packings, USA) and then separated on a $15 \mathrm{~cm}$ nanoflow analytical C18 column (PepMap $75 \mu \mathrm{m}$ id, $3 \mu \mathrm{m}, 100 \AA$ ) at a flow rate of $300 \mathrm{~nL} / \mathrm{min}$ on a nanoLC ultra 1D plus system (ABsciex, USA). Solvent A composition was $3 \%$ acetonitrile $(\mathrm{ACN}) \mathrm{v} / \mathrm{v}, 0.1 \%$ acetic acid $\mathrm{v} / \mathrm{v}$; whereas solvent B was $97 \%$ ACN v/v, 0.1\% acetic acid v/v. Peptide separation was performed with a linear gradient from 3 to $40 \%$ of solvent B for $20 \mathrm{~min}$, followed by an increasing to $90 \%$ of solvent B in $5 \mathrm{~min}$ and hold for $5 \mathrm{~min}$ (Zhu et al., 2010). The eluted peptides were directly sprayed into an LTQ Orbitrap XL mass spectrometer (Thermo Scientific Inc., Bremen, Germany). MS2 spectra were acquired in a data-dependent mode. An Orbitrap full MS scan (resolution: $3 \times 10^{4}$, mass range $400-1800 \mathrm{Da}$ ) was followed by 10 MS2 scans in the ion trap, which were performed via collision induced dissociation on the top 10 most abundant ions. Isolation window for ion selection was $3 \mathrm{Da}$. Normalized collision energy was set at $28 \%$. Dynamic exclusion time was $20 \mathrm{~s}$ ( $\mathrm{Li}$ et al., 2012a). The acquired mass spectra were searched against a Uniprot Zea mays database (62,860 entries, Jan-04-2013) using Mascot 2.2 search engine (http://www.matrixscience.com) with the following parameters: tryptic peptides with 1 missed cleavage site, mass tolerance of precursor ion of $10 \mathrm{ppm}$ and MS/MS ion of $0.8 \mathrm{Da}$, fixed carbamidomethylation of cysteine, variable methionine oxidation, asparagine and glutamine deamination. Unambiguous identification was done using Scaffold software V 3.0 (Proteome Software, OR, USA).

\section{BIOINFORMATICS ANALYSIS}

Functional classification of the proteins was done according to the clusters of orthologous groups for eukaryotic complete genomes (KOG) (ftp://ftp.ncbi.nih.gov/pub/COG/KOG/) (Tatusov et al., 2003) and the prediction of subcellular localization was done using a Plant-mPLoc tool (http://www.csbio.sjtu.edu.cn/bioinf/ plant-multi/) (Chou and Shen, 2010).The identified proteins were submitted to an $\mathrm{N}$-Glycosite tool for glycosylation site analysis (http://www.hiv.lanl.gov/content/sequence/GLYCOSITE/ glycosite.html) (Zhang et al., 2004). Prediction of the N-terminal presequences: chloroplast transit peptide (cTP), mitochondrial targeting peptide (mTP) and secretory pathway signal peptide (SP) was done using the TargetP 1.1 tool (http://www.cbs.dtu. $\mathrm{dk} /$ services/TargetP/) (Emanuelsson et al., 2000).

\section{RESULTS AND DISCUSSION \\ TWO DIMENSIONAL GEL ANALYSIS, PROTEIN IDENTIFICATION AND GLYCOPROTEIN (GP) DETECTION}

In order to determine the differences in glycosylation patterns of BETL between the wild type (WT) and the mutant (M), total protein extracts were prepared from the one-third lower part of maize kernels. For each sample, three biological replicates/gels were performed. The gels were stained with ProQ Emerald for glycoproteins, and then for total protein detection with Sypro Ruby stain. Figure 1 shows representative images of gels stained for potential glycoproteins and total proteins. A total

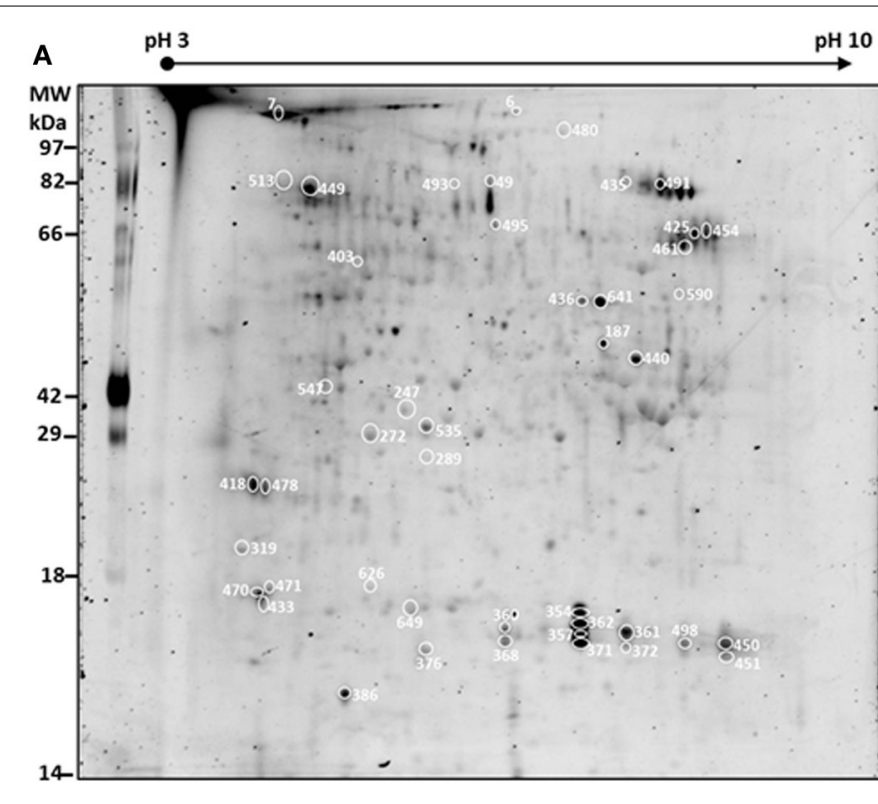

Glycoprotein stain

FIGURE 1 | Representative 2D-PAGE of BETL total protein extract stained with ProO emerald for glycoprotein detection (A) and Sypro ruby for total protein detection (B). The spots along with the spot

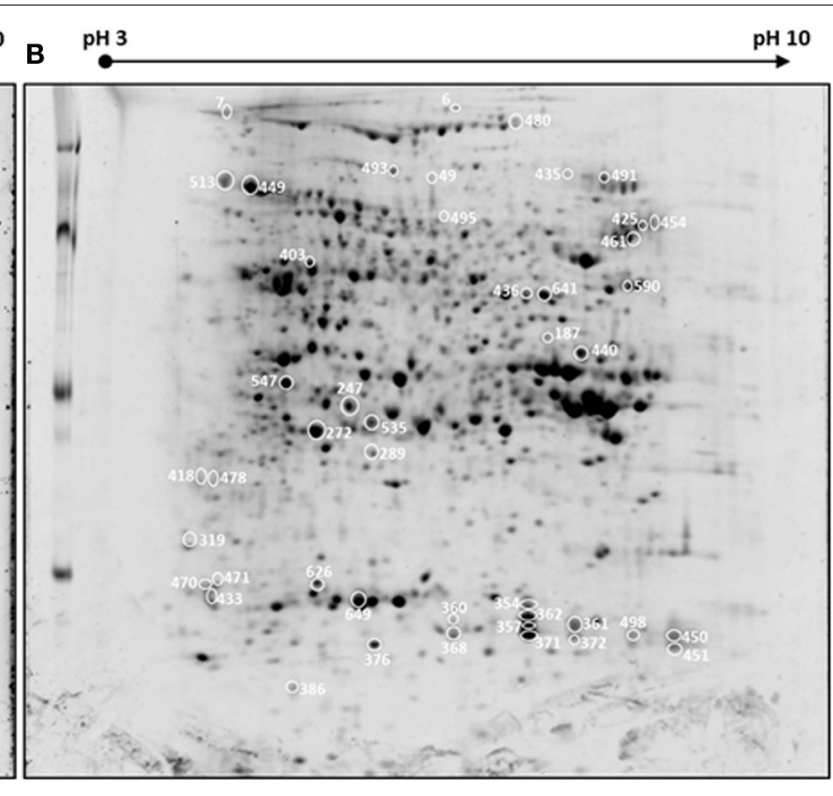

Total protein stain

numbers selected for protein identification by LC-MS/MS are marked with a circle. Numbers on various spots in each gel refer to the \#s shown in the 1 st column, Table $\mathbf{1}$. 
of 413 spots were detected in the four gels of the three replicates (Supplemental Figure 1) representing the wild type and mutant endosperm extracts; of these, 254 spots with $p$-values smaller than 0.05 based on ANOVA test were selected for further analysis.

Glycosylation of each protein spot was evaluated by their staining intensity with the GP stain that was normalized by the intensity of total protein stain (G/TP) for both WT and the mutant samples. Normalized glycosylation ratios are represented as $M_{(G / T P)} / W T_{(G / T P)}$ in Table 1. A total of 113 protein spots matched between the wild type and mutant gels, are shown in Supplemental Table 1. There are 45 spots (Figure 1) showing more than $20 \%$ increase or decrease in the normalized glycosylation level. Interestingly, only $4 \%$ of the 113 spots matched between WT and M showed increased GP ratios when comparing to the WT, while $36 \%$ showed decreased ratios (Supplemental Table 1).

Figure 2 shows four representative spots with dynamic changes in normalized glycosylation levels (G/TP). The majority of proteins have decreased glycosylation ratio that is calculated by $M_{(G / T P)} / W T_{(G / T P)}$; as demonstrated by spots 357 and 436 in Figure 2 with ratios of 0.69 and 0.71 , respectively. Only four spots showed $20 \%$ increased glycosylation in the mutant compared to the wild type. The spot 547 in Figure 2 is one of those proteins with glycosylation levels in the mutant being more than two-fold of those in the wild type. This indicates the relationship between glycosylation and protein abundance is complex. Figure 2 also includes an example of a protein, spot 185, with the glycosylation ratio of 0.97 that represented no significant change in glycosylation (Supplemental Table 1) in the two genotypes.

The 45 spots from the wild type and the mutant were excised and subjected to trypsin digestion and LC-MS/MS analysis. After database search using Mascot, the data were filtered in Scaffold software, and protein identification was considered valid if it had an overall $99 \%$ confidence and at least three unique peptides with $95 \%$ confidence. A total of 35 spots showed 69 comparable protein identifications between the WT and the M (Table 1). Some spots such as 272,436 , and 449 yielded multiple protein identifications due to the overlapping nature of proteins with similar molecular weights and isoelectric points (pIs). Several proteins were also reported by Zhu et al. (2006) in a similar proteomic study of root elongation zone in maize. Conversely, the same proteins were identified from multiple spots, e.g., spots 425,454 , and 461 as subtilisin-like protease, spots 357, 362, and 371 as Rhicadhesin receptor, and spots 440 and 449 as ER luminal binding protein. Differential post-translational modifications may account for these isoforms (Satoh et al., 2002). Alternative splicing is known to create multiple RNAs from a single gene that increase the proteome diversity. In maize, $19.2 \%$ of the total expressed genes are reported to be alternatively spliced (Barbazuk et al., 2008); thus various protein isoforms encoded by the same gene or its homologs may have alternative sizes and/or pIs.

Although nearly all the identified proteins (Table 1) exhibited close correlations between experimental and reported pIs, some did show discrepancy between the experimental molecular weights and theoretical molecular weights (e.g., spots 376, 454, and 493). These variations can be attributable to several factors, such as the lack of full length cDNA sequences or misannotation for these proteins; some of the cDNA sequences may have different splicing or degraded products, and post-translational modifications like glycosylation, which can also alter the molecular weights. Out of the 69 proteins presented in Table 1, 39 have been reported to be glycosylated.

\section{FUNCTIONAL CLASSIFICATION}

Functional classification of the identified proteins (Table 1) was performed according to the clusters of orthologous groups for eukaryotic complete genomes (KOG, Tatusov et al., 2003). Thirteen different categories were found: (I) Post-translational modification, protein turnover, chaperone functions; (II) carbohydrate metabolism and transport; (III) Amino acid metabolism and transport; (IV) Energy production and conversion; (V) Translation; (VI) RNA processing and modification; (VII) Nucleotide metabolism and transport; (VIII) Signal transduction; (IX) Coenzyme metabolism; (X) Secondary metabolites biosynthesis, transport and catabolism; (XI) Defense mechanisms; (XII) General functional prediction only; (XIII) No KOG related; as shown in Figure 3A.

Category I (Post-translational modification, protein turnover, chaperone functions) was the most represented category that included 15 proteins such as ER luminal binding protein (spots 440 and 449, Table 1), glutathione transferase (spot 362), heat shock proteins (spots 449 and 513), proteasome subunits (spots 376 and 433), chaperone proteins (spot 449), vignain (spot 440), subtilisin like protease (spots 454, 461, and 425), and WD repeat (spot 491). Interestingly, all proteins represented in the 10 spots are glycosylated as reported previously in other organisms (Table 1, the last column for the references); however, all showed reduced normalized glycosylation ratio except for the heat shock protein 70 (spot 513) with a ratio of 1.19 . These spots showed a total protein ratio, $M_{(T P)} / W T_{(T P)}$, of 1.0 or slightly higher (Table 1), suggesting that the reduced glycosylation in the mutant was not associated with the reduced abundance of these proteins.

Protein glycosylation is accomplished when the lipid (dolichol)-linked oligosaccharide transfers the carbohydratecontaining structure $\left(\mathrm{Glc}_{3} \mathrm{Man}_{9} \mathrm{GLcNAc}_{2}\right)$ to nascent peptides in the ER (Howell, 2013).Several studies have shown that the glucose residues on the lipid linked oligosaccharide facilitate the in vitro transfer of the oligosaccharide to the protein although it is not an absolute requirement (Kornfeld and Kornfeld, 1985). Cells starved of glucose or in energy deprivation state fail to produce $\mathrm{Glc}_{3} \mathrm{Man}_{9} \mathrm{GlcNAc}_{2}-\mathrm{P}-\mathrm{P}-\mathrm{Dol}$; instead, they accumulate Man ${ }_{9} \mathrm{GlcNAc}_{2}$ lipid linked species that were associated with the decrease in protein glycosylation in thyroid slices (Spiro et al., 1983). The accumulation of defective saccharide-lipid linked carrier upon different stresses varies according to cell type. In the BETL region of the $m n 1$ mutant kernels, the low glucose content may lead to defective or low levels of the dolichol-linked oligosaccharide causing a reduction of the normal glycosylation process associated as a general trend of low glycosylation ratios when compared with the WT.

Table 1 depicts proteins with a high total protein ratio when comparing to the wild type, including heat shock proteins (spots 


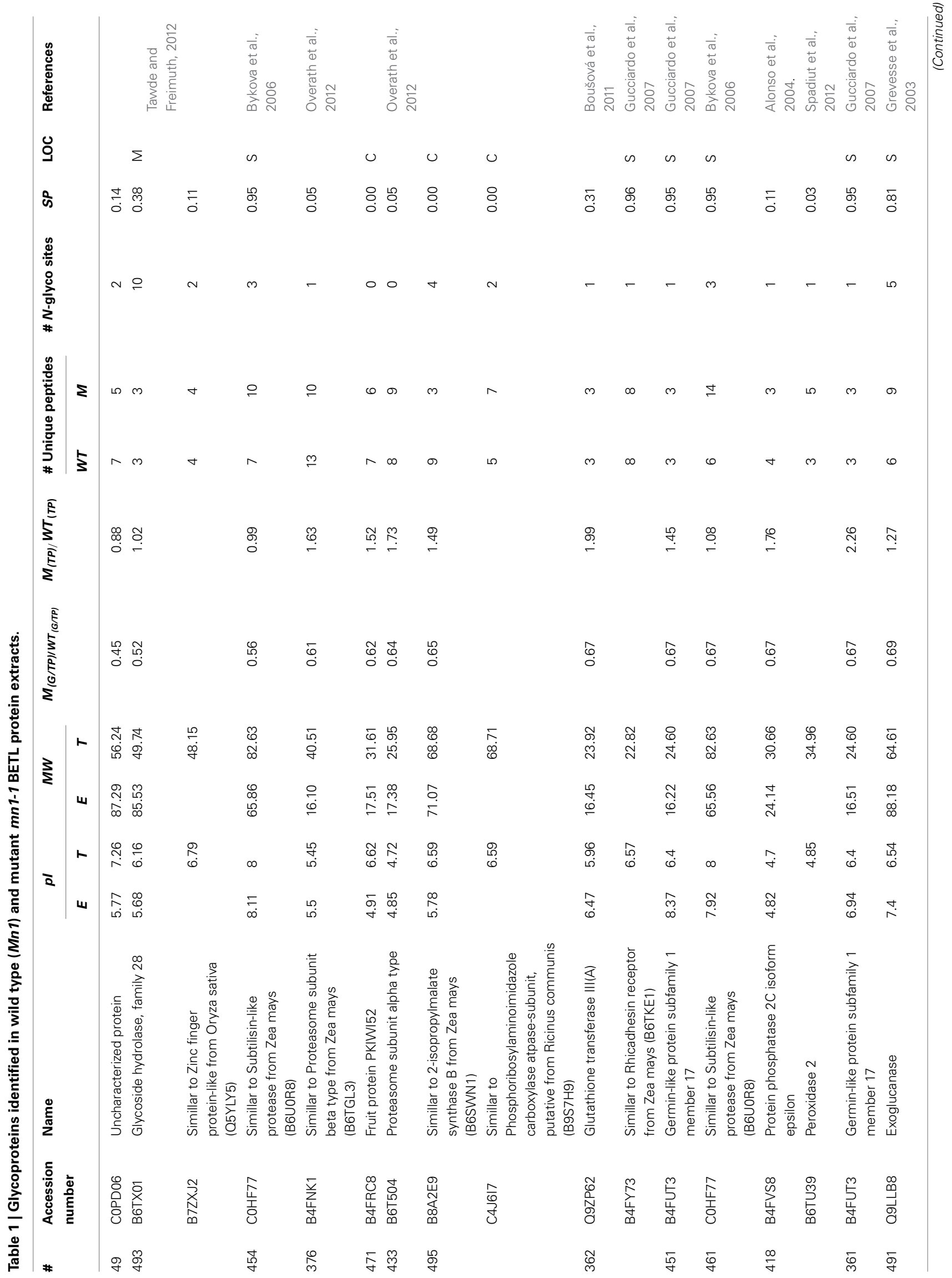




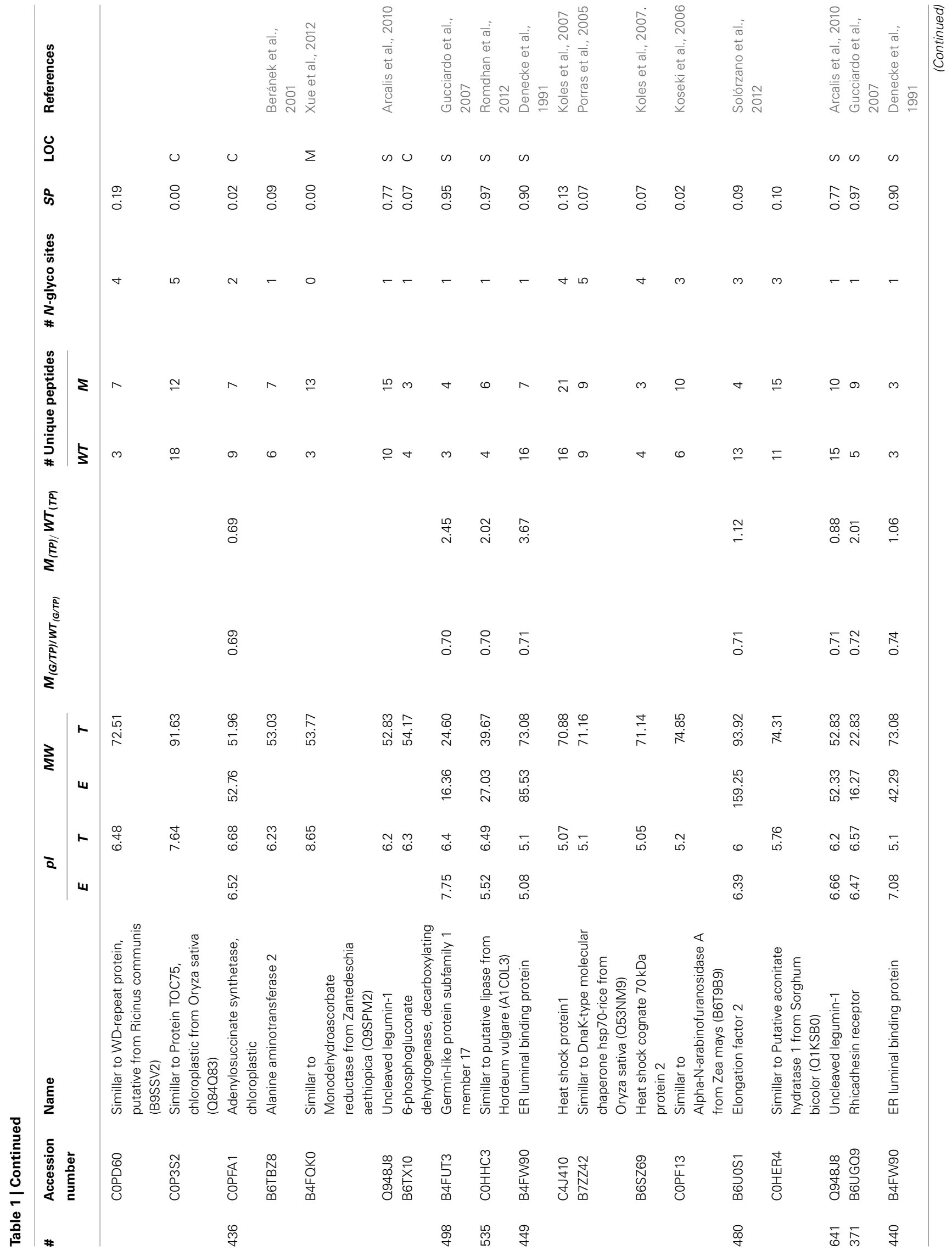




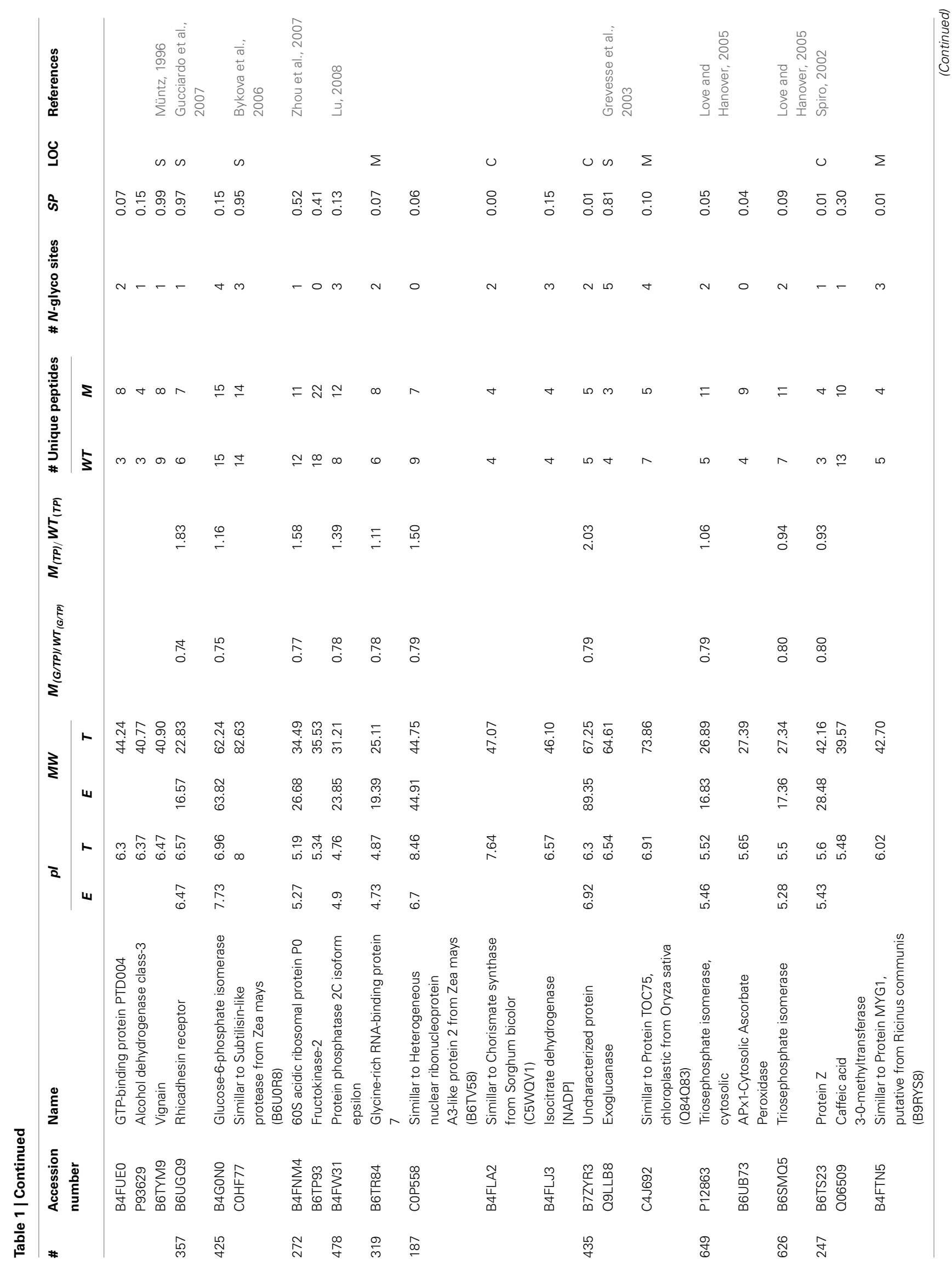




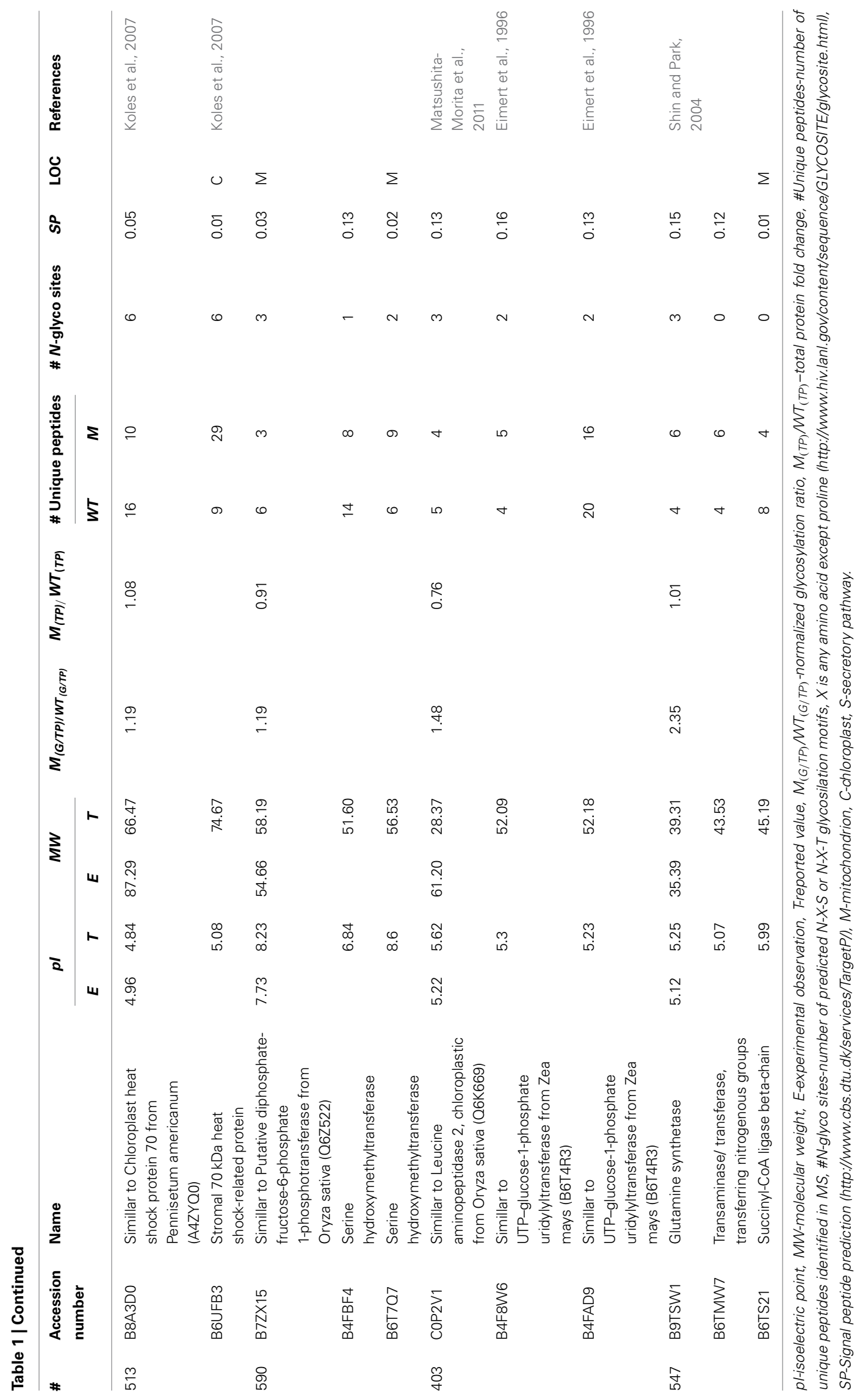




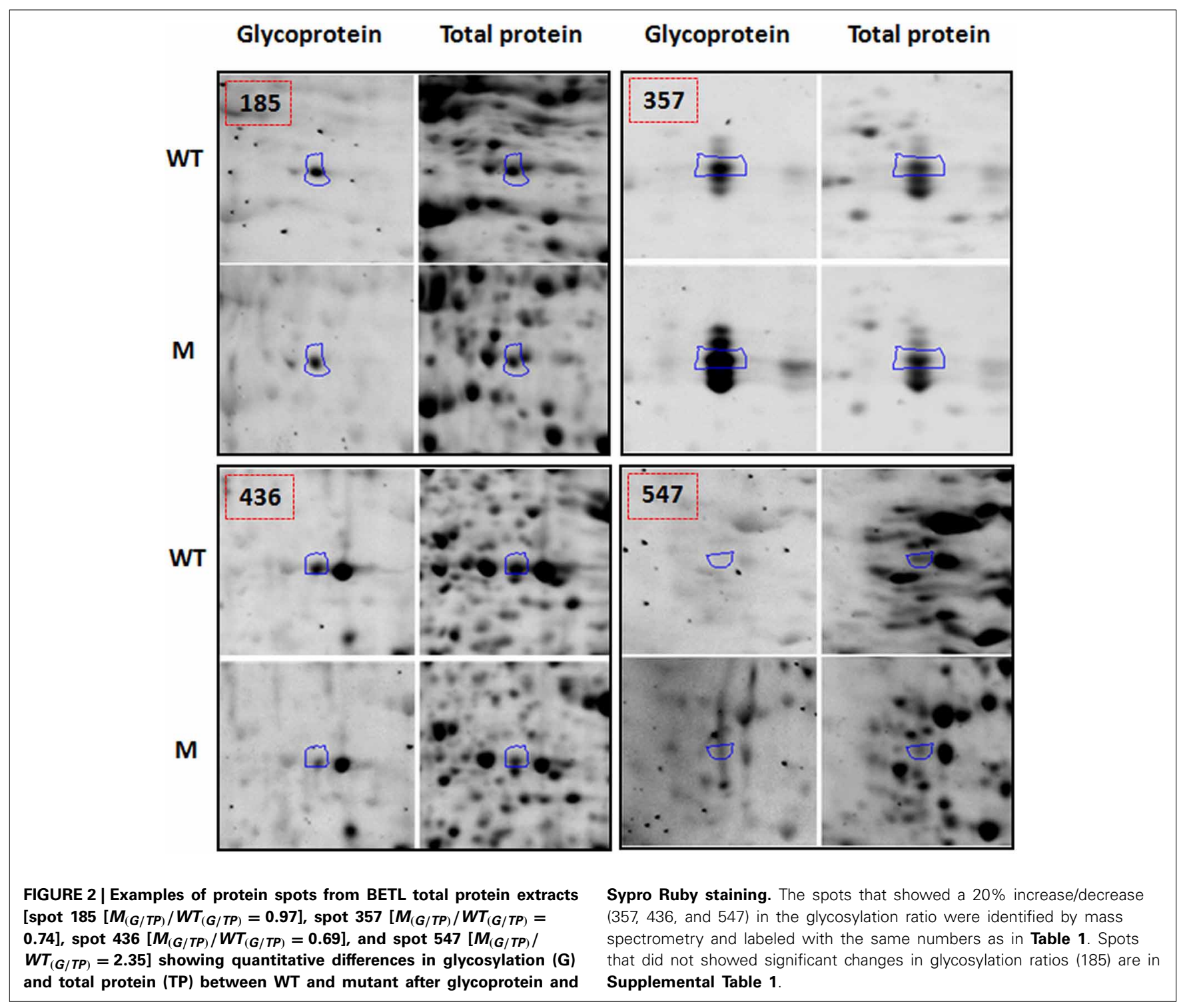

449 and 513), glutathione transferase III (spot 362) and proteasome (spots 376 and 433). Proteomic studies in developing seeds of Brassica campestri $L$ reported that $23.4 \%$ of the total proteins are involved in protein processing and degradation (Li et al., 2012b).

One of the main protein folding machineries in protein processing is the $N$-glycan dependent folding pathway (Howell, 2013). After the $\mathrm{Glc}_{3} \mathrm{Man}_{9} \mathrm{GlcNAc}_{2}$ core is transferred to the nascent polypeptide by the oligosaccharide transferase (OST), the Glc $\alpha-1,2$, and $\alpha-1,3$ are removed by the glucosidase I and II, then calreticulin/calnexin along with protein disulfide isomerase (PDI) help in the proper folding of the protein. Folded proteins are released by glucosidase which cleaves off the last glucose $\alpha$ 1,3 and are finally secreted. Proteins that are not properly folded are sensed by UDP-glucose:glycoprotein glucosyltransferase, and they can be reglucosylated to reenter the calreticulin/calnexin mediated folding cycle; where $\mathrm{N}$-glycosylation plays an important role in the endoplasmic reticulum quality control (ERQC).
We hypothesized that ER stress was induced in the BETL region due to the observed low protein $\mathrm{N}$-glycosylation, and since $N$-glycans are recognized along several steps in the folding process of proteins, low $\mathrm{N}$-glycosylation may lead to accumulation of unfolded/misfolded proteins that triggers the UPR response to mitigate the ER stress. These observations are consistent with Howell (2013) that UPR in plants is associated with upregulation of genes involved in protein folding and endoplasmic reticulum associated degradation (ERAD).

We observed four Hsp1 and Hsp70 proteins (spots 449 and $513)$; some with a high protein ratio in the $m n 1$ mutant kernels when compared with the WT; these proteins are reported to be involved in protein targeting to the mitochondria and chloroplasts (Kriechbaumer et al., 2012), along with ER luminal binding proteins (spots 440 and 449), proposed to be involved in protein body assembly within the ER (Li et al., 2012b), supporting the hypothesis of ER stress and UPR process as a response of the defective glycosylation process occurring in the BETL region. 

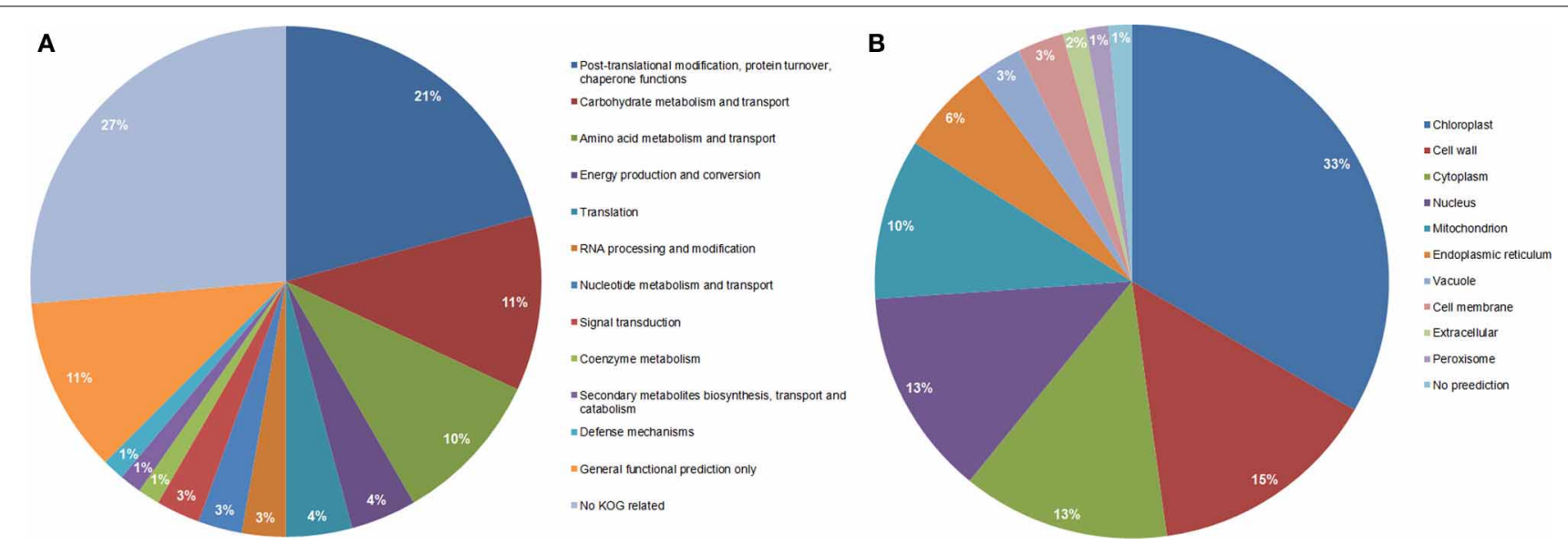

FIGURE 3 | Functional classification (A), and subcellular localization prediction (B), of the 69 proteins identified by LC-MS/MS in total protein extracts.

In addition to UPR response, the degradation of proteins via the ubiquitination-mediated pathway is an important mechanism in plant growth and development, and is responsible for the degradation of abnormal peptides and short-lived cellular regulators; controlling many processes that allow rapid response to intracellular signals (Sadanandom et al., 2012).This pathway is also related the ERAD by sensing glycoproteins that fail to fold into a native state. The alpha mannosidase interfere the reglucosylation cycles and removes the $\alpha-1,6$ linked mannose from the core oligosaccharide linked to a glycoprotein. The mannose trimmed glycoprotein is recognized by a series of luminal proteins such as Lectin OS9 and HRD3 and then exported to the cytosol to be degraded via ubiquitinilation mediated pathway (Howell, 2013). The observation of proteasome subunit alpha and beta (spots 433 and 376 respectively) in a high total protein ratio in the $m n 1$ mutant compared to the WT kernels suggest that $m n 1$ kernels are undergoing ER stress due to low concentration of glucose in the BETL region.

A correlation between ER stress and programed cell death (PCD) is also described in plants (Zuppini et al., 2004). PCD occurs when internal contents of a cell are engulfed in the vacuole, leading to the tonoplast rupture and release of vacuolar hydrolytic enzymes. The tonoplast rupture is mediated by vacuolar processing enzymes that have caspase-like activity (Howell, 2013). Along with the observed proteins related to ER stress, UPR, and ERAD processes, we found that the subtilisin-like protease (spots 425,454 , and 461) also have a reported caspase-like activity (Vartapetian et al., 2011). This protein showed a low normalized glycosylation level and no change in the total protein ratio in the $m n 1$ mutant compared to the WT, suggesting that ER stress might regulate PCD through under-glycosylation in the $m n 1$ mutant BETL region. Overall, the reduced glycosylation levels of many of the above proteins may also affect diverse metabolic and cellular functions in developing seeds.

Carbohydrate catabolism and transport, the second most represented group in the functional classification (Figure 3A), is composed of eight proteins in the glycolysis pathway, pentose pathway, fructose and mannose metabolism and starch synthesis (spots 272, 403 with two proteins, 425, 436, 590, 626, and 649). The enzymes that participate in glycolysis pathway showed low ratios of glycosylation in the $m n 1$ mutant when compared to WT and no change in the total protein ratio (Table 1). Several glycolytic enzymes among other protein/enzymes are reported to be modified by $O$-GlcNAc in various systems (Love and Hanover, 2005). The enzymes that participate in glycolysis are of special interest, due to the greatly reduced levels of hexoses resulting from the INCW2-deficiency in the BELT region of the mutant.

One of the proteins involved in carbohydrate catabolism is glucose-6-phosphate-isomerase (spot 425). It catalyzes the conversion of glucose-6-phosphate to fructose 6-phosphate, an important step in the hexoamine biosynthetic pathway. We observed that the glycosylation ratio of glucose-6-phosphateisomerase was reduced $(\approx 0.76)$ and the total protein ratio was nearly the same $(\approx 1.16)$, suggesting that its enzymatic function and activity may be modulated through glycosylation. Cells can sense the level of a product, UDP-GlcNAc, in the hexoamine biosynthetic pathway as an indication of the level of glucose, the precursor that is used in the same pathway (Love and Hanover, 2005). Because glucose-6-phosphate-isomerase is an essential enzyme in the hexoamine biosynthetic pathway, we hypothesize that it plays an important role in maintaining the homeostasis in the cells in terms of nutrient levels in the $m n 1$ kernel. Further studies are needed in the characterization of this particular protein and its role in regulatory pathways.

Triosephosphate isomerase (spot 649) that catalyzes the interconversion of glyceraldehyde-3-phosphate to dihydroxyacetone phosphate was found in cytosolic and plastid isoforms with the same trend in glycosylation and total protein abundance as the glycolytic enzymes, in which glycosylation level goes down while the total protein level doesn't change significantly. For fructose and mannose metabolism, fructokinase-2 (spot 272) was found with a low glycosylation ratio but a high ratio in total protein $(\approx 1.5)$; while diphosphate-fructose-6-phosphate 1phosphotransferas (spot 590) was found with a high ratio of 
glycosylation $(\approx 1.2)$ and no significant change in the total protein ratio. The 6-phosphogluconate dehydrogenase (spot 436), a decarboxylating enzyme, participates in the pentose phosphate pathway (PPP) and was found with low ratios for both glycosylation and total protein. Significantly, Spielbauer et al. (2013), reported a subset of chloroplast-localized PPP enzymes to be not only present in endosperm amyloplasts but are also critical for starch and oil biosynthesis in developing seeds. The UTPglucose-1-phosphate uridylyltransferase (spot 403) is responsible for synthesis and pyrophosphorolysis of UDP-glucose, a key precursor of carbohydrate formation (including sucrose, cellulose, starch, glycogen and $\beta$-glucan biosynthesis). This protein showed one of the highest ratios in glycosylation but had a reduced ratio in total protein level. UGPase is highly abundant in cell wall membrane in barley and it is speculated to have a role in providing UDP-glucose for biosynthesis of cell wall components, including $\beta$-glucans and cellulose (Eimert et al., 1996).

Amino acid metabolism and transport was the third most important category in functional classification. There were six proteins involved in amino acid metabolism; 2-isopropylmalate synthase, alanine aminotransferase, chorismate synthase, serine hydroxymethyltransferase, transaminase and glutamine synthetase (spots 495, 436, 187, 590, and 547 for last two proteins). The first three enzymes showed a low glycosylation ratio but 2isopropylmalate synthase and chorismate synthase had a high protein abundance ratio (Table 1). The last three enzymes had high glycosylation ratios but did not change in protein levels, which suggests that glycosylation may play a role in the regulation of these enzymes. In rice seed development proteomics studies, Deng et al. (2013) observed a correlation between the accumulation of proteins involved in protein synthesis and turnover, protein folding and amino acid metabolism, in early stages of rice seed development, indicating an active turnover of proteins during early development stages; as observed in our work.

\section{SUBCELLULAR LOCATION OF THE IDENTIFIED PROTEINS}

When observing the subcellular location prediction of the common proteins between the wild type and the mutant (Figure 3B), the chloroplast was the most represented with a $33 \%$ contribution of the total proteins identified, followed by the cell wall proteins $(15 \%)$ and cytoplasm (13\%). The chloroplast protein group consists of a very wide spectrum of different proteins that are involved in energy production and conversion, amino acid metabolism and transport, nucleotide metabolism and transport, carbohydrate metabolism and transport, and post-translational modification-protein turnover-chaperone functions.

All cell wall associated proteins showed low glycosylation level in the $m n 1$ mutant compare to the WT, as expected. The cell wall group was composed of 10 proteins; three subtilisin-like proteases that have post-translational modification, protein turnover, and chaperone functions (spots 425, 454, and 461) did not show any significant change in their total protein ratio. The other seven proteins did not belong to any KOG related group and were germinin-like proteins (GLPs), rhicadhesin receptor, and alpha$N$-arabinofuranosidase A (spots 357, 361, 362, 371, 449, 451, and 498 ), It has been reported that about $40 \%$ of all known GLPs are cell wall proteins; and all GLPs contain N-terminal secretory sequences that relate them strongly to the cell wall/extracellular matrix targeting (Breen and Bellgard, 2010). GLPs have been studied as defense molecules in different plant species, conditions and diseases due to their high resistance to protease, heat, SDS and extreme $\mathrm{pH}$. Several reports identified GLPs in diverse environmental conditions, such as salt, aluminum, drought stresses, fungal pathogen attacks, bacteria and virus infections (Breen and Bellgard, 2010). A special class of GLPs that is almost exclusively found in cereals is characterized by an oxalate oxidase (OXO) activity; meanwhile, a barley GLP reported by Bernier and Berna (2001) presents a different ADP glucose enzyme activity that leads to the hypothesis of its involvement in the control of metabolic flow toward starch, cell wall polysaccharides, glycoproteins and glycolipids in plants (Rodríguez-López et al., 2001). In addition, Gucciardo et al. (2007) isolated a pea GLP that showed similarity in its $\mathrm{N}$-terminus with a rhicadhesin recepetor. The GLP mRNA was expressed in non-conventional locations for rhicadhesin receptors such as in nodules and the expanding cells adjacent to the nodule meristem and in the nodule epidermis. This protein is demonstrated to have a superoxide dismutase activity and show resistance to high temperature among other stresses (Breen and Bellgard, 2010). All GLP proteins showed an increased protein ratio in the $m n 1$ mutant kernel, suggesting an upregulation due to the stress caused by the glucose-deficiency in BETL region.

Eight proteins of cytosolic location (spots 362, 403, 418, 425, 440, 480, 491, and 547) are described in Table 1 and Figure 3B were found in the experiment. These proteins have a variety of functions such as amino acid metabolism and transport; carbohydrate metabolism and transport; post-translational modification, protein turnover, chaperone functions; secondary metabolites biosynthesis; transport and catabolism; and translation. Glutathione transferase III(A), peroxidase 2, and a likeWD-repeat protein (spots 362, 418, and 491; respectively) showed low normalized glycosylation level but an increase in the total protein ratio. These proteins are related to oxidative stress. In a previous study (Silva-Sanchez et al., 2013), proteins related to gluthatione metabolism were up-regulated, in the $m n 1$ kernels, suggesting a potential redox regulation by glutathione. Elongation factor 2, alcohol dehydrogenase class-3 and glucose-6-phosphate isomerase (spots 425,440, and 480; respectively) showed a low normalized glycosylation level and nearly no change in their total protein ratio. These observations suggest that their regulation may be mediated through their glycosylation. A protein similar to UTP-glucose-1-phosphate uridylyltransferase (UGPUT) from Zea mays (B6T4R3, spot 403) showed a high normalized glycosylation ratio $(\approx 1.48)$ but a low total protein ratio $(\approx 0.76)$. This protein plays an important role in the biosynthesis of cell wall polysaccharides as well as in the synthesis of the carbohydrate moiety for glycolipid and glycoproteins (Kleczkowski et al., 2004). Glutamine synthetase (GS) (spot 547) showed the highest level of normalized glycosylation $(\approx 2.35)$ but no change in total protein ratio $(\approx 1.01)$. Cytosolic GS participate in seed development by assimilating ammonium in sink tissues probably through the asparagine catabolism as a possible source of ammonium (Bernard and Habash, 2009). The high glycosylation levels of UGPUT and GS suggest a complex mode of post-translational 
regulation in the plant. It is interesting to add that glycosylation of cytosolic proteins has been reported previously. Haltiwanger et al. (1992) described that several cytoplasmic and nuclear proteins undergo $\mathrm{O}$-glycosylation, which is highly dynamic in nature and is known to response to various stimuli in the media, in a similar way to phosphorylation responses. These processes are thus far well known in yeast or animal models (Spiro, 2002; Love and Hanover, 2005) although there is some research done in plants (Thornton et al., 1999; Love and Hanover, 2005 and references there in).

\section{N-GLYCOSYLATION PREDICTION AND SECRETORY PATHWAY}

For all of the proteins present in Table 1, we predicted the number of probable $N$-glycosylation sites based on the N-X-S, N-X-T, or NX[ST]Z motifs, where $\mathrm{X}$ can be any amino acid residues except proline using the $N$-glycosite tool (Zhang et al., 2004). A total of 48 proteins showed at least one predicted $N$-glycosylation site in their sequence. Those proteins that did not show any predicted $N$-glycosylation sites potentially have other types of unusual or rare glycosylation or are not studied/reported as glycoproteins yet. Although some proteins that showed at least one predicted $N$-glycosylation site, they may have been reported with other types of glycosylation. For example, the proteasome alpha subunit (spot 433) has been reported to be O-glycosylated in mouse (Overath et al., 2012); elongation factor 2 (spot 480) is an O-glycosylated protein in human cervical cancer cells (Solórzano et al., 2012), triosaphosphate isomerase (Spots 626 and 649) (Love and Hanover, 2005); and protein Z showed O-glycosylation in human plasma (Spiro, 2002). O-glycosylation occurs in a great variety of proteins that are involved in key nuclear and cytoplasmic activities. Similar to phosphorylation, O-GlcNAc modification occurs on Ser or Thr residues. O-GlcNAc is interchangeable with phosphorylation. These two modifications have similar roles in biological functions as well. O-GlcNAc modification is associated to a variety of regulatory activities such as carbohydrate metabolism, signaling, transcription and translation, and stress response (Love and Hanover, 2005).

In order to investigate whether the proteins are related to the secretory pathway and have the potential of being glycosylated or not, the identified proteins from the 45 spots in Table 1 were subjected to signal peptide prediction using the TargetP tool (Emanuelsson et al., 2000). According to the prediction, 17 proteins showed the highest scores for SP and have signal peptides. Examples of these proteins included rhicadhesin receptor (spots 357, 362, and 371), ER luminal binding protein (spots 440 and 449), GLP's (spots 361, 451, and 498), subtilisin-like protease (spots 425, 454, and 461). Many of these proteins are cell wall proteins or membrane proteins and are known to be glycosylated (Denecke et al., 1991; Bykova et al., 2006; Koseki et al., 2006; Gucciardo et al., 2007). For proteins with relative low scores for signal peptide prediction, eight proteins were assigned to mitochondria while 10 were located in the chloroplasts. The majority of these proteins have not been reported as glycoproteins. For the proteins that were not assigned neither to mitochondria or chloroplast; the low score on the SP prediction could indicate that these proteins have no classical secretion signal (Radhamony and Theg, 2006), and may follow so-called unconventional secretion based on alternative models of secretion independent of ER and Golgi route (Zhang and Schekman, 2013).

\section{CONCLUSIONS}

The study of glycosylated proteins in the total protein extracts of BETL from wild type and the $m n 1$ mutant revealed the deficiency of the mutant in the glycosylation process. The identified proteins that participate actively in post-translational modifications, protein turnover and chaperone functions may indicate the ER stress and UPR in the mutant due to the defective glycosylation processes. Carbohydrate metabolism related proteins showed in general low glycosylation ratios, suggesting that their enzymatic functions and activities may be regulated by the glycosylation levels through the hexosamine pathway. Low glycosylation ratios were also found in cell wall proteins of the mutant, which represent most of the plant defense proteins and structural protein-crosslink. More studies are needed to fully understand the mechanism underlying protein glycosylation, sugar sensing and plant survival.

\section{ACKNOWLEDGMENTS}

We thank Mr. Q-B Li and Mrs Ran Zheng for excellent technical assistance, and Drs B-H Kang and B. Rathinasabapathi for critical review of the manuscript.

\section{SUPPLEMENTARY MATERIAL}

The Supplementary Material for this article can be found online at: http://www.frontiersin.org/journal/10.3389/fpls.2014. 00063/abstract

\section{Supplemental Figure 1 | Overview of glycoprotein stain $(A, B)$ vs. total} protein stain $(C, D)$ of wild type $(A, C)$ and mutant $(B, D)$.

Supplemental Table 1 | Selection of spots to be analyzed by mass spectrometry. Spots in bold showed a significant variation of $20 \%$ and were chosen for mass spectrometry. GLY/G and TP stand for glycoproteins and total proteins.

\section{REFERENCES}

Alonso, A., Sasin, J., Bottini, N., Friedberg, I., Friedberg, I., Osterman, A., et al. (2004). Protein tyrosine phosphatases in the human genome. Cell 117, 699-711. doi: 10.1016/j.cell.2004.05.018

Arcalis, E., Stadlmann, J., Marcel, S., Drakakaki, G., Winter, V., Rodriguez, J., et al. (2010). The changing fate of a secretory glycoprotein in developing maize endosperm. Plant Physiol. 153, 693-702. doi: 10.1104/pp.109.152363

Barbazuk, W. B., Fu, Y., and McGinnis, K. M. (2008). Genome-wide analysis of alternative splicing in plants: opportunities and challenges. Genome Res. 18, 1381-1392. doi: 10.1101/gr.053678.106

Beránek, M., Drsata, J., and Palicka, V. (2001). Inhibitory effect of glycation on catalytic activity of alanine aminotransferase. Mol. Cell. Biochem. 218, 35-39. doi: 10.1023/A:1007280913732

Bernard, S. M., and Habash, D. Z. (2009). The importance of cytosolic glutamine synthetase in nitrogen assimilation and recycling. New Phytol. 182, 608-620. doi: 10.1111/j.1469-8137.2009.02823.x

Bernier, F., and Berna, A. (2001). Germins and germin-like proteins: plant do-all proteins. But what do they do exactly? Plant Physiol. Biochem. 39, 545-554. doi: 10.1016/S0981-9428(01)01285-2

Boušová, I., Prùchová, Z., Trnková, L., and Dršata, J. (2011). Comparison of glycation of glutathione S-transferase by methylglyoxal, glucose or fructose. $\mathrm{Mol}$. Cell. Biochem. 357, 323-330. doi: 10.1007/s11010-011-0903-5

Breen, J., and Bellgard, M. (2010). Germin-like proteins (GLPs) in cereal genomes: gene clustering and dynamic roles in plant defence. Funct. Integr. Genomics. 10, 463-476. doi: 10.1007/s10142-010-0184-1 
Bykova, N. V., Rampitsch, C., Krokhin, O., Standing, K. G., and Ens, W. (2006). Determination and characterization of site-specific $N$-glycosylation using MALDI-Qq-TOF tandem mass spectrometry: case study with a plant protease. Anal. Chem. 78, 1093-1103. doi: 10.1021/ac0512711

Cheng, W. H., and Chourey, P. S. (1999). Genetic evidence that invertasemediated release of hexoses is critical for appropriate carbon partitioning and normal seed development in maize. Theor. Appl. Genet. 98, 485-495. doi: $10.1007 / \mathrm{s} 001220051096$

Cheng, W. H., Taliercio, E. W., and Chourey, P. S. (1996). The Miniaturel seed locus of maize encodes a cell wall invertase required for normal development of endosperm and maternal cells in the pedicel. Plant Cell 8, 971-983.

Chou, K. C., and Shen, H. B. (2010). Plant-mPLoc: a top-down strategy to augment the power for predicting plant protein subcellular localization. PLoS ONE 5:e11335. doi: 10.1371/journal.pone.0011335

Chourey, P. S., Jain, M., Li, Q. B., and Carlson, S. J. (2006). Genetic control of cell wall invertase in developing endosperm of maize. Planta 223, 159-167. doi: 10.1007/s00425-005-0039-5

Chourey, P. S., Li, Q. B., and Cevallos-Cevallos, J. (2012). Pleiotropy and its dissection through a metabolic gene Miniature $(\mathrm{Mnl})$ that encodes a cell wall invertase in developing seeds. Plant Sci. 184, 45-53. doi: 10.1016/j.plantsci.2011.12.011

Davis, R. W., Smith, J. D., and Cobb, B. G. (1990). A light and electron-microscope investigation of the transfer cell region of maize caryopses. Can. J. Bot. 68, 471-479. doi: 10.1139/b90-063

Denecke, J., Goldman, M. H., Demolder, J., Seurinck, J., and Botterman, J. (1991). The tobacco luminal binding protein is encoded by a multigene family. Plant Cell 3, 1025-1035.

Deng, Z. Y., Gong, C. Y., and Wang, T. (2013). Use of proteomics to understand seed development in rice. Proteomics 13, 1784-1800. doi: 10.1002/pmic.201200389

Eimert, K., Villand, P., Kilian, A., and Kleczkowski, L. A. (1996). Cloning and characterization of several cDNAs for UDP-glucose pyrophosphorylase from barley (Hordeum vulgare) tissues. Gene 170, 227-232. doi: 10.1016/03781119(95)00873-X

Emanuelsson, O., Nielsen, H., Brunak, S., and von Heijne, G. (2000). Predicting subcellular localization of proteins based on their N-terminal amino acid sequence. J. Mol. Biol. 300, 1005-1016. doi: 10.1006/jmbi. 2000.3903

Grevesse, C., Lepoivre, P., and Jijakli, M. H. (2003). Characterization of the exoglucanase-encoding gene PaEXG2 and study of its role in the biocontrol activity of Pichia anomala strain K. Phytopathology 93, 1145-1152. doi: 10.1094/PHYTO.2003.93.9.1145

Gucciardo, S., Wisniewski, J. P., Brewin, N. J., and Bornemann, S. (2007). A germinlike protein with superoxide dismutase activity in pea nodules with high protein sequence identity to a putative rhicadhesin receptor. J. Exp. Bot. 58, 1161-1171. doi: $10.1093 /$ jxb/erl282

Haltiwanger, R. S., Kelly, W. G., Roquemore, E. P., Blomberg, M. A., Dong, L. Y., Kreppel, L., et al. (1992). Glycosylation of nuclear and cytoplasmic proteins is ubiquitous and dynamic. Biochem. Soc. Trans. 20, 264-269.

Howell, S. H. (2013). Endoplasmic reticulum stress responses in plants. Annu. Rev. Plant Biol. 64, 477-499. doi: 10.1146/annurev-arplant-050312-120053

Hurkman, W. J., and Tanaka, C. K. (1986). Solubilization of plant membrane proteins for analysis by two-dimensional gel electrophoresis. Plant Physiol. 81, 802-806. doi: 10.1104/pp.81.3.802

Kang, B. H., Xiong, Y., Williams, D. S., Pozueta-Romero, D., and Chourey, P. S. (2009). Miniaturel-encoded cell wall invertase is essential for assembly and function of wall-in-growth in the maize endosperm transfer cell. Plant Physiol. 151, 1366-1376. doi: 10.1104/pp.109.142331

Kleczkowski, L. A., Geisler, M., Ciereszko, I., and Johansson, H. (2004). UDPglucose pyrophosphorylase. An old protein with new tricks. Plant Physiol. 134, 912-918. doi: 10.1104/pp.103.036053

Koles, K., Lim, J. M., Aoki, K., Porterfield, M., Tiemeyer, M., Wells, L., et al. (2007). Identification of N-glycosylated proteins from the central nervous system of Drosophila melanogaster. Glycobiology 17, 1388-1403. doi: 10.1093/gly$\mathrm{cob} / \mathrm{cwm} 097$

Kornfeld, R., and Kornfeld, S. (1985). Assembly of asparagine-linked oligosaccharides. Annu. Rev. Biochem. 54, 631-664. doi: 10.1146/annurev.bi.54.070185. 003215

Koseki, T., Miwa, Y., Mese, Y., Miyanaga, A., Fushinobu, S., Wakagi, T., et al. (2006). Mutational analysis of $\mathrm{N}$-glycosylation recognition sites on the biochemical properties of Aspergillus kawachii alpha-L-arabinofuranosidase 54. Biochim. Biophys. Acta 1760, 1458-1464. doi: 10.1016/j.bbagen.2006.04.009

Kriechbaumer, V., von Löffelholz, O., and Abell, B. M. (2012). Chaperone receptors: guiding proteins to intracellular compartments. Protoplasma 249, 21-30. doi: 10.1007/s00709-011-0270-9

LeClere, S., Schmelz, E. A., and Chourey, P. S. (2008). Cell wall invertase-deficient miniature 1 kernels have altered phytohormone levels. Phytochemistry 69, 692-699. doi: 10.1016/j.phytochem.2007.09.011

LeClere, S., Schmelz, E. A., and Chourey, P. S. (2010). Sugar levels regulate tryptophan-dependent auxin biosynthesis in developing maize kernels. Plant Physiol. 153, 306-318. doi: 10.1104/pp.110.155226

Li, J., Ferraris, J. D., Yu, D., Singh, T., Izumi, Y., Wang, G., et al. (2012a). Proteomic analysis of high $\mathrm{NaCl}$-induced changes in abundance of nuclear proteins. Physiol. Genomics 44, 1063-1071. doi: 10.1152/physiolgenomics.00068.2012

Li, W., Gao, Y., Xu, H., Zhang, Y., and Wang, J. (2012b). A proteomic analysis of seed development in Brassica campestri L. PLOS ONE 7:e50290. doi: 10.1371/journal.pone.0050290

Liu, J. X., and Howell, S. H. (2010). Endoplasmic reticulum protein quality control and its relationship to environmental stress responses in plants. Plant Cell 22, 2930-2942. doi: 10.1105/tpc.110.078154

Love, D. C., and Hanover, J. A. (2005). The hexosamine signaling pathway: deciphering the "O-GlcNAc code." Sci. STKE 2005, re13. doi: $10.1126 /$ stke.3122005re13

Lu, G. (2008). Regulation of Local Signaling by Type 2c Protein Phosphatases. Dissertations, Academic, UCLA, Molecular Cellular, and Integrative Physiology, 66-67.

Matsushita-Morita, M., Tada, S., Suzuki, S., Hattori, R., Marui, J., Furukawa, I., et al. (2011). Overexpression and characterization of an extracellular leucine aminopeptidase from Aspergillus oryzae. Curr. Microbiol. 62, 557-564. doi: 10.1007/s00284-010-9744-9

Miller, M. E., and Chourey, P. S. (1992). The maize invertase-deficient miniature-1 seed mutation is associated with aberrant pedicel and endosperm development. Plant Cell. 4, 297-305.

Müntz, K. (1996). Proteases and proteolytic cleavage of storage proteins in developing and germinating dicotyledonous seeds. J. Exp. Botany. 47, 605-622. doi: 10.1093/jxb/47.5.605

Offler, C. E., McCurdy, D. W., Patrick, J. W., and Talbot, M. J. (2003). Transfer cells: cells specialized for a special purpose. Annu. Rev. Plant Biol. 54, 431-454. doi: 10.1146/annurev.arplant.54.031902.134812

Overath, T., Kuckelkorn, U., Henklein, P., Strehl, B., Bonar, D., Kloss, A., et al. (2012). Mapping of $O$-GlcNAc sites of 20 s proteasome subunits and Hsp90 by a novel biotin-cystamine tag. Mol. Cell Proteomics 11, 467-477. doi: 10.1074/mcp.M111.015966

Porras, F., Urrea, F., Ortiz, B., Martínez-Cairo, S., Bouquelet, S., Martínez, G., et al. (2005). Isolation of the receptor for the Amaranthus leucocarpus lectin from human T lymphocytes. Biochim. Biophys. Acta 1724, 155-162. doi: 10.1016/j.bbagen.2005.03.014

Radhamony, R. N., and Theg, S. M. (2006). Evidence for an ER to Golgi to chloroplast protein transport pathway. Trends Cell. Biol. 16, 385-387. doi: 10.1016/j.tcb.2006.06.003

Rodríguez-López, M., Baroja-Fernández, E., Zandueta-Criado, A., Moreno-Bruna, B., Muñoz, F. J., Akazawa, T., et al. (2001). Two isoforms of a nucleotidesugar pyrophosphatase/phosphodiesterase from barley leaves (Hordeum vulgare 1.) are distinct oligomers of hvglp1, a germin-like protein. FEBS Lett. 490, 44-48.

Romdhan, I. B., Fendri, A., Frikha, F., Gargouri, A., and Belghith, H. (2012). Purification, physico-chemical and kinetic properties of the deglycosylated Talaromyces thermophilus lipase. Int. J. Biol. Macromol. 51, 892-900. doi: 10.1016/j.ijbiomac.2012.06.034

Ruan, Y. L., Jin, Y., Yang, Y. J., Li, G. J., and Boyer, J. S. (2010). Sugar input, metabolism, and signaling mediated by invertase: roles in development, yield potential, and response to drought and heat. Mol Plant. 3, 942-955. doi: $10.1093 / \mathrm{mp} / \mathrm{ssq} 044$

Ruiz-May, E., Thannhauser, T. W., Zhang, S., and Rose, J. K. C. (2012). Analytical technologies for identification and characterization of the plant N-glycoproteome. Front. Plant Sci. 3:150. doi: 10.3389/fpls.2012.00150

Sadanandom, A., Bailey, M., Ewan, R., Lee, J., and Nelis, S. (2012). The ubiquitinproteasome system: central modifier of plant signalling. New Phytol. 196, 13-28. doi: $10.1111 /$ j.1469-8137.2012.04266.x 
Satoh, K., Takeuchi, M., Oda, Y., Deguchi-Tawarada, M., Sakamoto, Y., Matsubara, K., et al. (2002). Identification of activity-regulated proteins in the postsynaptic density fraction. Genes Cells 7, 187-197. doi: 10.1046/j.1356-9597.2001. 00505.x

Sheffield, J., Taylor, N., Fauquet, C., and Chen, S. (2006). The cassava (Manihot esculenta Crantz) root proteome: protein identification and differential expression. Proteomics 6, 1588-1598. doi: 10.1002/pmic. 200500503

Shin, D., and Park, C. (2004). N-terminal extension of canine glutamine synthetase created by splicing alters its enzymatic property. J. Biol. Chem. 279, 1184-1190. doi: 10.1074/jbc.M309940200

Silva-Sanchez, C., Chen, S., Zhu, N., Li, Q.-B., and Chourey, P. S. (2013). Proteomic comparison of basal endosperm in maize miniature 1 mutant and its wild-type Mn1. Front. Plant Sci. 4:211. doi: 10.3389/fpls.2013.00211

Solórzano, C., Angel Mayoral. M., de los Angeles, C. M., Berumen, J., Guevara, J., Raúl Chávez, F., et al. (2012). Overexpression of glycosylated proteins in cervical cancer recognized by the Machaerocereus eruca agglutinin. Folia Histochem. Cytobiol. 50, 398-406. doi: 10.5603/FHC.2012.0054

Spadiut, O., Rossetti, L., Dietzsch, C., and Herwig, C. (2012). Purification of a recombinant plant peroxidase produced in Pichia pastoris by a simple 2-step strategy. Protein Expr. Purif. 86, 89-97. doi: 10.1016/j.pep.2012.09.008

Spielbauer, G., Li, L., Romisch-Margl, L., Do, T., Fouquet, R., Fernie, A. R., et al. (2013). Chlorplast-localized 6-phosphogluconate dehydrogensae is critical for maize starch accumulation. J. Exp. Bot. 64, 2231-2242. doi: 10.1093/jxb/ert082

Spiro, R. G. (2002). Protein glycosylation: nature, distribution, enzymatic formation, and disease implications of glycopeptide bonds. Glycobiology 12, 43R-56R. doi: $10.1093 /$ glycob/12.4.43R

Spiro, R. G., Spiro, M. J., and Bhoyroo, V. D. (1983). Studies on the regulation of the biosynthesis of glucose-containing oligosaccharide-lipids. Effect of energy deprivation. J. Biol. Chem. 258, 9469-9476.

Tatusov, R. L., Fedorova, N. D., Jackson, J. D., Jacobs, A. R., Kiryutin, B., Koonin, E. V., et al. (2003). The COG database: an updated version includes eukaryotes. BMC Bioinformatics 4:41. doi: 10.1186/1471-2105-4-41

Tawde, M. D., and Freimuth, P. (2012). Toxic misfolding of Arabidopsis cellulases in the secretory pathway of Pichia pastoris. Protein Expr. Purif. 85, 211-217. doi: 10.1016/j.pep.2012.08.009

Thornton, T. M., Swain, S. M., and Olszewski, N. E. (1999). Gibberellin signal transduction presents ellipsisthe SPY who O-GlcNAc'd me. Trends Plant Sci. 4, 424-428. doi: 10.1016/S1360-1385(99)01485-5

Vartapetian, A. B., Tuzhikov, A. I., Chichkova, N. V., Taliansky, M., and Wolpert, T. J. (2011). A plant alternative to animal caspases: subtilisin-like proteases. Cell Death Differ. 18, 1289-1297. doi: 10.1038/cdd.2011.49

Vaughn, K. C., Talbot, M. J., Offler, C. E., and McCurdy, D. W. (2007). Wall ingrowths in epidermal transfer cells of Vicia faba cotyledons are modified primary walls marked by localized accumulations of arabinogalactan proteins. Plant Cell Physiol. 48, 159-168. doi: 10.1093/pcp/pcl047
Vitale, A., and Boston, R. S. (2008). Endoplasmic reticulum quality control and the unfolded protein response: insights from plants. Traffic 9, 1581-1588. doi: 10.1111/j.1600-0854.2008.00780.x

Xue, Y. L., Miyakawa, T., Sawano, Y., and Tanokura, M. (2012). Cloning of genes and enzymatic characterizations of novel dioscorin isoforms from Dioscorea japonica. Plant Sci. 183, 14-19. doi: 10.1016/j.plantsci.2011.10.021

Zhang, M., Gaschen, B., Blay, W., Foley, B., Haigwood, N., Kuiken, C., et al. (2004). Tracking global patterns of N-linked glycosylation site variation in highly variable viral glycoproteins: HIV, SIV, and HCV envelopes and influenza hemagglutinin. Glycobiology 14, 1229-1246. doi: 10.1093/glycob/cwh106

Zhang, M., and Schekman, R. (2013). Unconventional secretion, unconventional solutions. Scie 340, 559-561. doi: 10.1126/science. 1234740

Zhou, H., Liu, Y., Chui, J., Guo, K., Shun, Q., Lu, W., et al. (2007). Investigation on glycosylation patterns of proteins from human liver cancer cell lines based on the multiplexed proteomics technology. Arch. Biochem. Biophys. 459, 70-78. doi: 10.1016/j.abb.2006.10.027

Zhu, J., Chen, S., Alvarez, S., Asirvatham, V. S., Schachtman, D. P., Wu, Y., et al. (2006). Cell wall proteome in the maize primary root elongation zone. I. Extraction and identification of water-soluble and lightly ionically bound proteins. Plant Physiol. 140, 311-325. doi: 10.1104/pp.105.070219

Zhu, M., Simons, B., Zhu, N., Oppenheimer, D. G., and Chen, S. (2010). Analysis of abscisic acid responsive proteins in Brassica napus guard cells by multiplexed isobaric tagging. J. Proteomics 73, 790-805. doi: 10.1016/j.jprot.2009.11.002

Zuppini, A., Navazio, L., and Mariani, P. (2004). Endoplasmic reticulum stressinduced programmed cell death in soybean cells. J. Cell Sci. 117, 2591-2598. doi: $10.1242 /$ jcs.01126

Conflict of Interest Statement: The authors declare that the research was conducted in the absence of any commercial or financial relationships that could be construed as a potential conflict of interest.

Received: 07 August 2013; accepted: 07 February 2014; published online: 26 February 2014.

Citation: Silva-Sanchez C, Chen S, Li J and Chourey PS (2014) A comparative glycoproteome study of developing endosperm in the hexose-deficient miniature1 (mn1) seed mutant and its wild type Mn1 in maize. Front. Plant Sci. 5:63. doi: 10.3389/fpls. 2014.00063

This article was submitted to Plant Physiology, a section of the journal Frontiers in Plant Science.

Copyright (C) 2014 Silva-Sanchez, Chen, Li and Chourey. This is an open-access article distributed under the terms of the Creative Commons Attribution License (CC BY). The use, distribution or reproduction in other forums is permitted, provided the original author(s) or licensor are credited and that the original publication in this journal is cited, in accordance with accepted academic practice. No use, distribution or reproduction is permitted which does not comply with these terms. 